\title{
Relationship between Weight Pre-Pregnancy and Weight Gain during Pregnancy with Preterm Birth
}

\author{
Dönmez $\mathrm{S}^{*}$ and Güner $\mathrm{O}^{2}$
}

\author{
${ }^{1}$ Department of Nursing, Institute of Health Sciences, Gaziantep University, Gaziantep-Turkey \\ ${ }^{2}$ Faculty of Nursing, Ege University, İzmir-Turkey
}

*Corresponding author: Dönmez S, Research Assistant, Department of Nursing, Institute of Health Sciences, Gaziantep University, Gaziantep-Turkey, Tel: +90 342 3606060, E-mail: donmezsevgul@gmail.com

Citation: Dönmez S, Güner Ö (2017) Relationship Between Weight Pre-Pregnancy and Weight Gain During Pregnancy with Preterm Birth. J Nutr Health Sci 4(2): 207. doi: 10.15744/2393-9060.4.207

Received Date: January 24, 2017 Accepted Date: August 05, 2017 Published Date: August 08, 2017

\begin{abstract}
Worldwide alarming increase of obesity prevalence has led the WHO to take into consideration as one of the most serious global health problems of the $21^{\text {st }}$ century. $40 \%$ of women worldwide are overweight. The leading causes of obesity prevalence in women more often becaouse during pregnancy and before pregnancy they gain excess weight. The rapid increase of obesity prevalence especially among women in the World cause women begin pregnancy overweight or obese and this can cause problems about pregnancy and birth. One of the most important of these problems are the threat of premature birth. Each year it is estimated that 15 million babies born before 37 weeks and it is increasing day by day. The relationship between weight gain during pregnancy of preterm birth and weight before pregnancy are discussed in the literature.Some studies suggest that obesity or less weight than usual increases the risk of preterm birth and some suguggest it is not affect. Two studies done with 4735 and 8266 women shows that overweight and obesity increase the risk of preterm birth. As a result, despite efforts to reduce preterm birth, prematüre birth and infant mortality rate leads to an increase in morbidity and the incidence is increasing. İt is thought that one of the most important cause of preterm birth balancing BMI prepregnancy and during pregnancy contribute positively maternal and neonatal outcomes. Pregnancy is not a good time to lose weight. Predicted weight gain during pregnancy should be set at the begining of the monitoring.
\end{abstract}

Keywords: Preterm birth; Weight pre-pregnancy; Weight gain during pregnancy; Obesity

\section{Introduction}

Since mankind has been struggling with starvation, famine and poverty throughout the history, excessive weight and obesity were perceived as the indications of health and wealth in almost all communities. Although starvation and poverty are still a major problem, health problems associated with both insufficient nourishment and infectious diseases have been replaced with health problems brought by overnutrition and obesity [1]. While obesity was considered a developed countries'problem at the beginning, it has been inevitable with increased income levels in developing countries, adaption of the western life style, decrease in energy consumption when energy intake increases and finally through migration from rural to urban. Furthermore, the decrease in physical activities due to facilitated life style in transportation, production and farming domains, the changes in nourishment habits in modern life (especially fast-food), rapidly eaten unhealthy foods and a nourishment style rich in fat, carbohydrates and refined sugar and poor in vegetable fibers in parallel with the spread of technological tools (cell-phone, television, computer, home theatre, etc.) have significantly contributed to the increase in obesity [1-4]. Consequently, the prevalence of obesity is constantly increasing regardless of east-west or rich-poor community discrimination. Today, the second most important cause of preventable deaths after smoking is obesity [4]. Therefore, obesity seems a multifactor chronic disease that reduces quality of life. This worrisome increase in obesity prevalence worldwide has led World Health Organization to consider obesity as one of the most serious global health problems in $21^{\text {st }}$ century [4]. The Organisation for Economic Cooperation and Development (OECD) said that nearly one in two adults and one in six children are overweight or obese in OECD countries. While adult obesity rates are highest in the United States, Mexico, New Zealand and Hungary, they are lowest in Japan and Korea. Obesity rates are projected to increase further by 2030, and Korea and Switzerland are the countries where obesity rates are projected to increase at a faster pace. Social inequalities in overweight and obesity are strong, especially among women [5]. 
According to WHO, there are 1.9 billion over-weighted adults in 2014 and more than 600 million of them are obese. While $40 \%$ of women are over-weighted in the world, $29.3 \%$ of the women are over-weighed and $24.5 \%$ are obese in Turkey [6,7]. Studies carried out on this topic have demonstrated in Turkish women that the reduced physical activity, higher birth rate, longer lactation periods, accompanying diabetes and hypertension, lower income and education levels have significantly influenced the obesity $[8,9]$. However, over weight gained during pre-and-peri-gestational periods in women is one of the leading causes of obesity seen [10].

Gaining weight during pregnancy has categorized the BMI (in terms of $\mathrm{kg} / \mathrm{m}^{2}$ ) as less than normal $(<18.5)$, normal (between 18.5 and 24.9), above normal (between 25 and 29.9) and obese (>30). According to BMI (Body Mass Index), total weight gain (Ib) is recommended as less than normal (28-40), normal (25-35), above normal (15-25) and obese (11-20) (Table 1) [11,12].

\begin{tabular}{|c|c|c|c|}
\hline Pre-gestational Health & BMI $\left(\mathbf{k g} / \mathbf{m}^{2}\right)$ & $\begin{array}{c}\text { Recommended Range of Total } \\
\text { Weight }(\mathbf{l b})\end{array}$ & $\begin{array}{c}{ }^{*} \text { Recommended Rates of } \\
\text { Weight Gain in the Second and } \\
\text { Third Trimesters (Ib) (Mange } \\
\text { Range[Ib/wk]) }\end{array}$ \\
\hline Less than Normal & $<18.5$ & $28-40$ & $1(1-1.3)$ \\
\hline Normal & $18.5-24.9$ & $25-35$ & $1(0.8-1)$ \\
\hline Above Normal & $25-29.9$ & $15-25$ & $0.6(0.5-0.7)$ \\
\hline $\begin{array}{c}\text { Obese (includes all } \\
\text { classes) }\end{array}$ & $>30$ & $11-20$ & $05(0.4-0.6)$ \\
\hline
\end{tabular}

${ }^{\star}$ Calculations assume a 1.1-4.4 Ib weight gain the first trimester

Table 1: The Guideline for Weight Gain during Pregnancy According to BMI $[11,12]$

Since obesity seen throughout pregnancy is related to a number of complications, it is considered as a higher risky situation and as an indication is thought to have a crucial importance in occurrence of unwanted gestational outcomes [10,13,14]. Preconception obesity rate varies between 1.8 and $25.3 \%$ worldwide [15]. All over the world, women to initiate pregnancy with a weight above normal or as an obese in accordance with the rapid increase in the prevalence of over-weight and obesity among women have more birth-related problems. The most important one of these problems is the threat for preterm [13,16-18].

\section{Association with Obesity, Weight Pre-Pregnancy and Weight Gain During Pregnancy of Pre- term Birth}

The threat for preterm that is called preterm birth is defined as a birth action that starts beginning from the first day of last menstruation between 20 and 37 weeks (140 and 259 days). "Premature labor" is defined as a delivery taking place between those weeks independent from the birth weight. It is estimated that 15 million babies are delivered before $37^{\text {th }}$ week each year and this rate is steadily increasing. In 2013, preterm was held responsible for the death of approximately 1 million children younger than 5 -year old. Preterm labor rate varies between 5 to $18 \%$ in 184 countries [19]. Preterm labors are responsible for more than $75 \%$ of perinatal mortalities and more than half of the long term morbidities [20,21].

Premature labors are also seen as the primary cause of mortality and morbidity in newborns. Although the advances in technology and patient monitoring, there is no a significant decrease in the incidence of premature actions and labors. Health centers and obstetricians attempt to reduce the preterm labor rate by considering the effects of premature labor on the early period of human health. In order to prevent preterm labor, high risk patients are intervened preconception and symptomatic patients during pregnancy [22]. Therefore, it is thought that reduction of factors that may cause risks by health professionals preconception will provide great advances about this subject. To this end, to predict and prevent preterm birth should be the essential goal. Especially, decreasing the body weight above normal preconception or preventing the preterm birth through controlled weight gain during pregnancy started to gain importance recently.

The number of studies examining the relationship between with preterm delivery of pre-pregnancy weight gain and weight gain in pregnancy is limited. Some studies reported that obesity, overweight or the weight less than normal have increased the risk for preterm labor; whereas others failed to show such an effect. ACOG indicates that obesity is associated with preterm delivery, but the relationship with spontaneous preterm delivery is controversial. Pregnancy is a period in which women experience significant changes in their body weights. BMI is one of the important factors affecting the prognosis of pregnancy. High or low $\mathrm{BMI}$ is associated with antenatal, intrapartum and postpartum complications (preeclampsia, gestational diabetes, preterm labor, postpartum hemorrhage) $[23,24]$. BMI is also one of the most significant factors related to preterm births in Central and Eastern Europe [25]. In a study carried out with 11323 pregnant women found that inadequate gestational weight gain and excessive gestational weight gain were independent risk factors for preterm birth compared with normal gestational weight gain [26,27]. Maternal and fetal outcomes such as low birth weight, macrosomia, birth rates of spontaneous preterm labor, cesarean delivery, maternal postpartum obesity have been found to be more healthy for pregnant women with body weight between the borders of The Institute of Medicine (IOM) [28]. Also, it is generally stated that obese women have a high risk for preterm labor, but low risk for spontaneous preterm labor. However, it is thought that the relationship between maternal obesity and preterm birth risk 
is complex and potentially influenced by other factors including age, parity, smoking and ethnicity. Although the mechanism by which obesity reduces the risk of spontaneous preterm labor is not fully understood, it is stated that obese women may have a lower level of spontaneous uterine activity compared to normal weight and weaker women [29]. Obese pregnant women are more likely to develop gestastional diabetes and preeclampsia causing maternal risk increasing the rates of preterm delivery [30]. In a systematic review of 49 studies, it was observed that as the BMI increases, the preterm delivery risk increases [31]. In a meta-analysis study carried out with 10171 obese preterm births in pregnant women with gestational weight gain over the indicated increased risk [32]. In another study it was found that gestational weight gain above the recommendations and moderate weight gain during pregnancy is associated with preterm [33,34]. In a study by Vivatkusol, et al., percentage of cesarean section was increased in the overweight and obese pregnant women; in contrast, the rate of preterm births showed an increase in underweight pregnant womens [35]. Also, in another study found that risk of preterm birth were high in the insufficient weight gain groups regardless of BMI [36]. Huang, et al. reported that excessive gestational weight gain among underweight pregnant women, insufficient gestational weight gain among obese pregnant women and excessive gestational weight gain in last trimester were important indicators of preterm birth [37]. Hannaford, et al. found that pregnant women who gained weight below recommendations and normal-weight patients who gained below recommendationwere twice as likely to deliver preterm [38]. Enomoto, et al. showed that poor weight gain in pregnancy correlated with a higher frequency preterm birth, preterm premature rupture of membranes, and spontaneous preterm birth. In a study carried out with 4735 women, the risks for preterm and cesarean section were significantly higher in obese pregnant women [14,39]. A study conducted with 8266 women living in Amsterdam found that overweight and obesity have increased the threat for preterm labor risk and the preterm labor risk was more prevalent in smoking and immigrant women [40]. In another study it was found that the risk for preterm birth has increased in obese pregnant women with singleton and multiple pregnancies [41]. In a study by Masho, et al., in over weighted and obese women the decreased weight gain throughout pregnancy was found to be associated with lesser spontaneous preterm labor and lesser early premature membrane rupture [42]. Moreover, in another study, obesity has increased the risk for preterm birth in nulliparous, black and Hispanic women. Contrary to these studies, other studies found higher risk for preterm labor in women with weight less than normal $[43,44]$. Ina study, Honest et al. reported that the weight preconception could not be helpful in predicting preterm labor [45]. In a study by Mamun, et al., the risk for preterm labor was found higher in women who had weight less than normal preconception or had gained insufficient weight during pregnancy, whereas the risk was lower in those who gained overweight during pregnancy [13]. In Sharifzadeh, et al's study, it was reported that there was a significant negative relationship between preterm labor and maternal body mass index (BMI) and the preterm birth was more frequently seen in women with reduced BMI [46]. In a study by Kosa, et al., both reduced and increased BMI preconception was found to be related to preterm labor [47]. Besides, in De Jongh, et al's study is was found that the normal BMI preconception was protective in Caucasion/non-Hispanic, Spanish and Asian pregnant women, but not in Black/non-Hispanic women [48].

\section{Conclusion and Recommendations}

Finally, despite attempts to reduce preterm labor the preterm labor still leads to increases in infant mortalities and mortalities and its incidence also continues to increase. It is thought that balancing BMI during preconception and pregnancy, which is one of the most important causes of preterm labor, will provide positive contributions to maternal and neonatal outcomes [14]. Pregnancy is not the right time for losing weight. Therefore, to encourage those women with higher BMI to lose weight preconception and become pregnant when they reached a suitable weight is very important in terms of prevention of potential problems. Furthermore, it is also important to both initiate pregnancy in a planned manner in the preconceptional period and make regular weight checks during pregnancy. The weight gain recommended during pregnancy should be determined at the beginning of follow-up, pregnant women should be informing of the nourishment and if necessary they should be referred to a dietitian. Co-operation with endocrinologists should be done for obese pregnancies with diabetes. Women must be training about nourishment, exercise and weight control during preconception and pregnancy. Since there are few studies carried out on the BMI at the preconception period, weight gain during pregnancy and complications in Turkey, more prospective studies are needed.

\section{References}

1. Tsigos C, Hainer V, Basdevant A, Finer N, Fried M, et al. (2008) Management of obesity in adults: European Clinical Practice Guidelines. Obesity Facts 1: 106-16.

2. Tsoi E, Shaikh H, Robinson S, Teoh TG (2010) Obesity in pregnancy: A major healthcare issue. Postgrad Med J 86: 617-23.

3. Shaikh H, Robinson S, Teoh TG (2010) Management of maternal obesity prior to and during pregnancy. Semin Fetal Neonatal Med 15: 77-82.

4. World Health Organization(2013) Obesity and overweight. WHO fact sheet No 311.

5. The Organisation for Economic Cooperation and Development (OECD). OECD Health Statistics 2017.

6. World Health Organization (2015) Obesity and overweight.

7. Turkey Statistical Institute (TUIK) (2015) Türkiye Sağlık Araştırması, 2014.

8. Gundogan K, Bayram F, Gedik V, Kaya A, Karaman A, et al. (2013) Metabolic syndrome prevalence according to ATP III and IDF criteria and related factors in Turkish adults Arch Med Sci 9: 243-53.

9. Sonmez A, Bayram F, Barcin C, Ozsan M, Kaya A, et al. (2013) Waist circumference cutoff points to predict obesity, metabolic syndrome, and cardiovascular risk in Turkish adults. Int J Endocrinol 2013: 767202.

10. Ata KK, Şahin NH (2015) Gebelik Öncesi Beden Kitle İndeksinin Perinatal ve Neonatal Sonuçlara Etkisi. Zeynep Kamil Tip Bülteni $46: 112-7$. 
11. American College of Obstetricians and Gynecologists (ACOG) (2013) Weight gain during pregnancy. Committee Opinion No. 548. Obstet Gynecol 121: 210-2.

12. Rasmussen KM, Yaktine AL (2009) Weight gain during pregnancy: reexamining the guidelines. Washington DC: National Academy Press.

13. Mamun AA, Callaway LK, O’calloghan MJ, Williams GM, Najman JM, et al. (2011) Associations of maternal prepregnancy obesity and excess pregnancy weight gains with adverse pregnancy outcomes and length of hospital stay. BMC Pregnancy Childbirth 11: 62.

14. Munim S, Maheen H (2012) Association of Gestational Weight Gain and Pre-Pregnancy Body Mass Index with Adverse Pregnancy Outcome. J Coll Physicians Surg Pak 22: 694-8.

15. Papachatzi E, Paparrodopoulos S, Papadopoulos V, Dimitriou G, Vantarakis A (2016) Pre-pregnancy maternal obesity in Greece: A case-control analysis. Early Hum Dev 93: 57-61.

16. Ding XX, Xu SJ, Hao JH, Huang K, Su PY, et al. (2016) Maternal pre-pregnancy BMI and adverse pregnancy outcomes among Chinese women: Results from the C-ABCS. J Obstet Gynaecol. 36: 328-32.

17. Reiss K, Breckenkamp J, Borde T, Brenne S, David M, et al. (2015) Contribution of overweight and obesity to adverse pregnancy outcomes among immigrant and non-immigrant women in Berlin, Germany. Eur J Public Health 25: 839-44.

18. Yanıkkerem E, Mutlu S (2012) Maternal Obezitenin Sonuçları ve Önleme Stratejileri [Maternal Obesity: Consequences and Prevention Strategies]. TAF Prev Med Bull 11: 353-64.

19. Blencowe H, Cousens S, Oestergaard MZ, Chou D, Moller AB, et al. (2012) National, regional, and worldwide estimates of preterm birth rates in the year 2010 with time trends since 1990 for selected countries: a systematic analysis and implications.. Lancet 379: 2162-72.

20. Goldenberg MD (2002) The management of preterm labor. Obstet Gynecol 100: 1020-37.

21. Onat T, Abalı R, Turgut NE, Çelik S, Boran AB, et al. (2014) 10-15 ve 20-25 Haftalarda Ölçülen Servikal Uzunluğunun Preterm Doğumu Öngörmedeki Yeri. İstanbul Med J 15: 35-9.

22. Kamalak Z, Simavlı S, Duvan İC, Turhan NÖ (2011) Preterm Eylem Yönetimi. Yeni Tip Dergisi 28: 13-6.

23. American College of Obstetricians and Gynecologists (ACOG) (2015) Obesity in pregnancy. ACOG Practice Bulletin No. 156. Obstet Gynecol 126: e112-22

24. Ekin A, Gezer C, Eftal C, Solmaz TU, Özeren M (2017) Gebelik Öncesi Vücut Kitle İndeksinin Perinatal Sonuçlara Etkisi [Effect of body mass index before pregnancy on perinatal outcomes]. Bakırköy Tip Dergisi 13: 20-5.

25. Arora CP, Kacerovsky M, Zinner B, Ertl T, Ceausu I, et al. (2015) Disparities and relative risk ratio of preterm birth in six Central and Eastern European centers. Croat Med J 56: 119-27.

26. Wise LA, Palmer JR, Heffner LJ, Rosenberg L (2010) Prepregnancy body size, gestational weight gain, and risk of preterm birth in African-American women. Epidemiology 2: 243-52.

27. Zhang DD, Tan DX, Wang B, Cai XN, Zhou AF, et al. (2016) Association between gestational weight gain and preterm birth: a retrospective epidemiological analysis in Wuhan. Chinese J Epidemiol 37: 1012-6.

28. Abrams, B. Altman, SL. Pickett, KE (2007) Pregnancy weight gain: still controversial. Am J Clin Nutr 71: $1233-41$.

29. McGuire W, Dyson L, Renfrew M (2010) Maternal obesity: consequences for children, challenges for clinicians and carers. Semin Fetal Neonatal Med 15: 108-12.

30. Farley DM, Choi J, Dudley DJ, Li C, Jenkins SL, et al. (2010) Placental amino acid transport and placental leptin resistance in pregnancies complicated by maternal obesity. Placenta 31: 718-24.

31. Salihu HM, Mbah AK, Alio AP, Clayton HB, Lynch O (2009) Low pre-pregnancy body mass index and risk of medically indicated versus spontaneous preterm singleton birth. Eur J Obstet Gynecol Reprod Biol 1: 119-23.

32. Faucher MA, Hastings-Tolsma M, Song JJ, Willoughby DS, Bader SG (2016) Gestational weight gain and preterm birth in obese women: a systematic review and meta-analysis. BJOG 123: 199-206.

33. Goldstein RF, Abell SK, Ranasinha S, Misso M, Boyle JA, et al. (2017) Association of Gestational Weight Gain With Maternal and Infant Outcomes: A Systematic Review and Meta-analysis. JAMA 317: 2207-25.

34. Leonard SA, Petito LC, Stephansson O, Hutcheon JA, Bodnar LM, et al. (2017) Weight gain during pregnancy and the black-white disparity in preterm birth. Ann Epidemiol 27: 323-8.

35. Vivatkusol Y, Thavaramara T, Phaloprakarn C (2017) Inappropriate gestational weight gain among teenage pregnancies: prevalence and pregnancy outcomes. Int J Womens Health 9: 347-52.

36. Kaimura M, Oda M, Mitsubuchi H, Ohba T, Katoh T (2017) Participant Characteristics in the Kumamoto University Regional Center of Japan Environment and Children's Study (JECS): Association of Pregnancy Outcomes with Pregestational Maternal Body Mass Index and Maternal Weight Gain during Pregnancy. Nihon Eiseigaku Zasshi 72: 128-34.

37. Huang A, Ji Z, Zhao W, Hu H, Yang Q, et al. (2016) Rate of gestational weight gain and preterm birth in relation to prepregnancy body mass indices and trimester: a follow-up study in China. Reprod Health 13: 93.

38. Hannaford KE, Tuuli MG, Odibo L, Macones GA, Odibo AO (2017) Gestational Weight Gain: Association with Adverse Pregnancy Outcomes. Am J Perinatol 34: $147-54$.

39. Enomoto K, Aoki S, Toma R, Fujiwara K, Sakamaki K, et al. (2016) Pregnancy Outcomes Based on Pre-Pregnancy Body Mass Index in Japanese Women. PLoS One 11: e0157081.

40. Djelantik AA, Kunst AE, van der Wal MF, Smit HA, Vrijkotte TG (2012) Contribution of overweight and obesity to the occurrence of adverse pregnancy outcomes in a multi-ethnic cohort: population attributive fractions for Amsterdam. BJOG 119: 283-90.

41. Lucovnik M, Blickstein I, Verdenik I, Trojner-Bregar A, Tu N (2015) Maternal obesity in singleton versus twin gestations: a population-based matched casecontrol study. J Matern Fetal Neonatal Med 28: 623-5.

42. Masho SW, Bishop DL, Munn M (2013) Pre-pregnancy BMI and weight gain: where is the tipping point for preterm birth?. BMC Pregnancy Childbirth 13: 120. 43. Gibbs RS., Karlan BY, Haney AF, Nygaard I (2008) Danforth's obstetrics and gynecology. Philadelphia: Lippincott Williams and Wilkins, 171.

44. Salihu H, Mbah AK, Alio AP, Kornosky JL, Whiteman VE, et al. (2010) Nulliparity and preterm birth in the era of obesity epidemic. J Matern Fetal Neonatal Med 23: 1444-50.

45. Honest H, Bachmann LM, Ngai C, Gupta JK, Kleijnen J, et al. (2005) The accuracy of maternal anthropometry measurements as predictors for spontaneous preterm birth a systematic review. Eur J Obstet Gynecol Reprod Biol 1: 11-20. 
46. Sharifzadeh F, Kashanian M, Jouhari S, Sheikhansari N (2015) Relationship between pre-pregnancy maternal BMI with spontaneous preterm delivery and birth weight. J Obstet Gynaecol 35: 354-7.

47. Kosa JL, Guendelman S, Pearl M, Graham S, Abrams B, et al. (2011) The Association Between Pre-pregnancy BMI and Preterm Delivery in a Diverse Southern California Population of Working Women. Matern Child Health J 15: 772-81.

48. de Jongh BE, Paul DA, Hoffman M, Locke R (2014) Effects of Pre-pregnancy Obesity, Race/Ethnicity and Prematurity. Matern Child Health J $18: 511-17$.

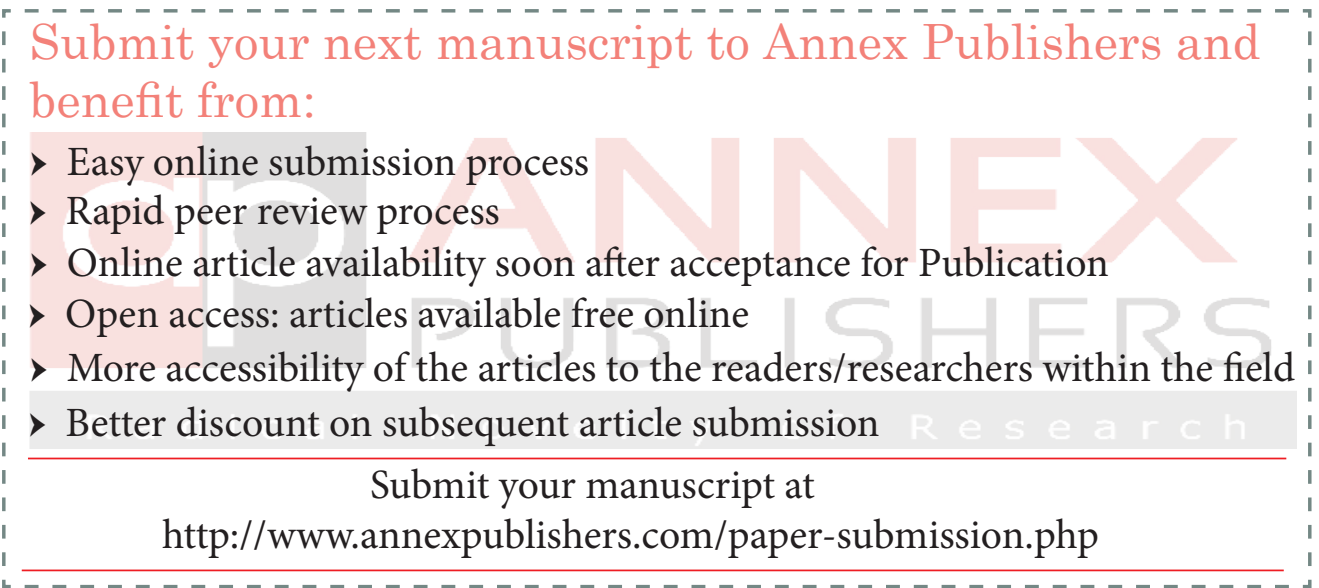

